\title{
Acute Occupational Hand Injuries With Their Social and Economic Aspects: A Hospital Based Cross Sectional Study
}

\author{
SM Rabiul Islam* \\ Department of Orthopaedic Surgery, Raja Isteri Pengiran Anak Saleha Hospital, Brunei \\ *Corresponding author: SM Rabiul Islam, FICS, Department of Orthopaedic Surgery, Raja Isteri Pengiran Anak Saleha (RIPAS) Hospital, Bandar Seri \\ Begawan, Brunei Darussalam, Brunei
}

Submission: 眥 November 08, 2017; Published: 倫 November 29, 2017

\begin{abstract}
Background: Hand injuries constitute a significant number of trauma patients all over the world. Advanced countries have well equipped hand surgery units with well-trained hand surgeons and paramedical staff. Hand injuries are more frequent in under developed countries with very little specialist care.

Objectives: The objectives of this study were to collect data to have knowledge about hand injuries in one of the largest hospital of Bangladesh in International Medical College Hospital (IMCH) Gazipur, to know the prevalence, handedness, mode and types of hand injuries and their socioeconomic impact.

Methods: Over a period of six months 325 patients of acute hand injuries were analysed and data were entered on prescribed preformed and analyzed using SPSS 11.5 software.

Results: There were 325 patients out of these, 310 were males and 15 were females. The mean age of all patients was 26.84 years ranging from 12-62 years? Considering the fractures there were 111 thumbs, 122 index, 45 middle, 3 ring and 40 little finger involvements. It was also seen that there were 37 amputations out of these 4 amputations were at or just distal to wrist level. Hand soft tissues included 162 skin injuries, 42 tendon injuries and 16 neurovascular injuries. Finally, according to procedures performed, there were 140 back slab applications, 148 wire fixations. According to type of anesthesia used, there were 175 local, 3 regional, 6 general anesthesias and in 141 no anesthesia was used.
\end{abstract}

Keywords: Hand injuries; Occupational injuries

\section{Introduction}

Hand is one of the most important structural assets of human body. Without human hands the most refined creation of human mind would be a mere theoretical concept. The other name of hand is earning tool. Loss of hand functions mean loss of earning capacity. For every important work in daily life, we need to use our hands. If someone losses his hand or hands, he becomes handicapped and cannot perform his normal functions of daily life properly [1]. Hand injuries are quite common in Bangladesh. Many occupations make a person vulnerable to hand injuries due to inexperience, lack of training, performing an unusual work task, working overtime, personal worries, feeling ill, malfunctioning equipment/ materials using different work methods, being distracted and rushing all contributing to the increased incidence of hand injuries in Bangladesh [2]. We know that all injures are preventable and if we can prevent such injuries, we may save the person from undue hospitalization, absence from work, undue social and economic burden and handicapped life [3].

Acute traumatic hand injuries in manual and occupational workers constitute a unique orthopedic challenge worldwide, because of the particular demands on the workers e.g. financial implication, administration pressure and self-esteem issues. A specialized management approach is often necessary [4]. Hand injuries are common and account for $5-10 \%$ of emergency department visits nationwide [5]. A lot of small industries are situated in and around Dhaka city like, plastic industry, leather industry, press machines, garments factories, metallic and paper cutting machines. Patients come with crush hand, some with lacerated soft tissues and bony injuries; some are coming with fingers or whole hand amputated. Manual workers work in a close environment without proper light and ventilation with long duty hours which leads to the workers crush hand injuries [6]. The aim of this study is to know the prevalence, handedness, mode and types of hand injuries and their socioeconomic impact. 


\section{Materials and Methods}

It was a cross sectional study conducted in Accident and Emergency Department, International Medical College Hospital Gazipur, Bangladesh. Data was collected over a period of six months from 1st Feb - 31st July 2012, a total 325 acute hand injury patients who attended during this period. Acute hand injuries within12 hours of occurrence and occupational hand injuries cases were included, Old cases more than 12 hours, Pediatric patients, Poly trauma patients with associated hand injuries and those patients requiring advance life support (ICU) care were excluded. All those who were satisfying inclusion criteria were included. Study participants were interviewed to collect information regarding their health, personal, occupational and morbidity particulars. A structured questionnaire was made for this study which specifically depicted age, gender, handedness, occupation, salary, dependent persons in the family, and help from social department. SPSS 11.5 data were analysed, selective tables and graphs were used to express the variables, descriptive statistics was used in the form of Mean, Mode, Standard deviation and range for numeric data and Rates and ratios were used to express the qualitative variables. Approval has been obtained from the hospital ethical committee (Ref. No. IMCH 123/45).

\section{Result}

There were 325 patients out of these, 310(95.37\%) were

Table 1: Frequency table for non-numeric data. males and 15(4.63\%) were females. The mean age of all patients were 26.84 years ranging from 12-62 years. Mostly patients were from urban areas i.e. 245 (75.61\%) as compared with rural i.e. $80(24.29 \%)$. According to socioeconomic status mostly patients were poor i.e. $271(83.6 \%)$ and illiterate $221(68.21 \%)$ patients were. In addition 139 (42.90\%) patients were labourers and 111 (34.26\%) were manual workers. Manual workers with dependent family members were more significant $(p$-value $=0.0026)$. According to characteristic of hand injuries type there were $82(25 \%)$ closed and $243(75 \%)$ open fractures. Moreover there were $130(40.12 \%)$ right side involvement out of these 128(98.46\%) were having dominant right side and 185(57.1\%) left side involvement and out of these $8(4.32 \%)$ were having their left side as dominant. Bilateral involvement was seen in $10(2.78 \%)$ patients only. According to injuries there were $111(34.25 \%)$ thumbs, $122(37.65)$ index, $45(1.89 \%)$ middle, $7(0.61 \%)$ ring and $40(12.34 \%)$ little finger involvements. We also analyzed that there were 37 (11.42\%) amputations out of these $4(1.23 \%)$ amputations were at or just distal to wrist level. According to soft tissues involvement, there were $162(50 \%)$ skin injuries, $41(12.65 \%)$ tendon injuries and $16(4.94 \%)$ neurovascular injuries. Finally, according to procedures there were 139 (42.90\%) back slab applications, 148(45.67\%) wire fixations remaining $38 \mathrm{soft}$ tissue procedures. According to type of anesthesia used, 175(54.01\%) local, 2(0.617\%) regional, 6(1.85\%) general anesthesia and in $142(43.51 \%)$ patient's anesthesia was not given (Table $1 \& 2$ ).

\begin{tabular}{|c|c|c|c|c|}
\hline Characteristic & Mean \pm Sd $(n=325)$ & Number & Percentage & ${ }^{*} \mathbf{P}$ Value \\
\hline Age & $26.8 * 10.7$ & & & \\
\hline \multirow{2}{*}{ Gender } & Male & 310 & 95.4 & $0.000^{*}$ \\
\hline & Female & 15 & 4.6 & $0.000^{*}$ \\
\hline \multirow{2}{*}{ Area } & Urban & 245 & 75.7 & $0.000^{*}$ \\
\hline & Rural & 80 & 24.3 & $0.000^{*}$ \\
\hline \multirow{3}{*}{ occupation } & Labourer & 139 & 42.9 & $0.000^{*}$ \\
\hline & Manual Worker & 112 & 34.26 & $0.000^{*}$ \\
\hline & others & 74 & 22.84 & $0.000^{*}$ \\
\hline \multirow{2}{*}{ SES } & Poor & 271 & 83.6 & $0.000^{*}$ \\
\hline & others & & & \\
\hline \multirow{2}{*}{ Literacy } & illiterate & 221 & 68.20 & $0.000^{*}$ \\
\hline & literate & 104 & 31.80 & \\
\hline
\end{tabular}

**Males, urban workers, labourers and manual workers, are statistically significant in hand injuries. 
Table 2: Characteristic of acute hand injury.

\begin{tabular}{|c|c|c|c|}
\hline Characteristic & Injury Category & Number & Percentage $\%$ \\
\hline \multirow{2}{*}{ Fracture Type } & Close & 82 & 25 \\
\hline & Open & 243 & 75 \\
\hline \multirow{3}{*}{ Side } & Right & 130 & 40.12 \\
\hline & Left & 185 & 57.1 \\
\hline & Bilateral & 10 & 2.78 \\
\hline \multirow{5}{*}{ Site of injury } & Thumb & 111 & 34.25 \\
\hline & Index & 122 & 37.65 \\
\hline & Middle & 45 & 13.89 \\
\hline & Ring & 7 & 1.87 \\
\hline & Little finger & 40 & 12.34 \\
\hline \multirow{3}{*}{ Tissue involve } & Skin & 162 & 50 \\
\hline & Tendon & 41 & 12.65 \\
\hline & NV injury & 16 & 4.94 \\
\hline \multirow{2}{*}{ Amputation } & Finger & 37 & 11.42 \\
\hline & Hand level of wrist & 4 & 1.23 \\
\hline \multirow{2}{*}{ Management Emergency Dept. } & Non operative & 139 & 42.90 \\
\hline & Operative & 186 & 47.10 \\
\hline \multirow{4}{*}{ Anaesthesia } & Local & 175 & 54.01 \\
\hline & Regional & 2 & 0.617 \\
\hline & General & 6 & 1.85 \\
\hline & No anaesthesia & 142 & 43.51 \\
\hline
\end{tabular}

\section{Discussion}

Hand injuries are frequent and reported for 5-10 out of 100 of emergency department visits [5]. In this study the prevalence of hand injuries was $14.5 \%$.There were 325 patients out of these, $310(95.37 \%)$ were males and $15(4.63 \%)$ were females. The mean age of all patients were 26.84 years ranging from 12-62year. Mostly patients were from urban areas i.e. $245(75.61 \%)$ as compared with rural i.e. $80(24.29 \%)$. According to socioeconomic status mostly patients were poor i.e. 271(83.6\%). Workers were from different geographical locations e.g. surrounding areas of Dhaka and nearby villages. Poor machine design, adverse work environment and personal risk factors are associated with only small proportions of occupational injury [7] these were the major contributing risk factors in present study. It was also noticed that wearing gloves had an insignificant protective effect on the occurrence of hand injury. In the study conducted by [7], external factors such as work and social conditions seemed to have less influence on time off work than expected, whereas advice from doctors, flashbacks and impairment symptoms were important determinants [7-13]. Injuries of the hand rarely are life threatening. However, the high incidence of disability from chronically painful or unstable joints is reflected by the fact that hand derangements account for $9 \%$ of all worker compensation claims. The costs for treating these injuries are considerable and include not only the direct costs of repair but also the indirect costs borne by the patient, his or her family, and society. These indirect costs include, for example, time off from work and costs incurred while seeking care [14]. Our industrial and agricultural systems have recognized limitations that predispose the workers to hand injuries. Lack of occupational safety protocols, lack of vocational training and young age at starting industrial/ agricultural life are among the factors that contribute to the causation of serious injuries in our set up. Regarding the risk of such injuries, a variety of factors which is responsible either directly or 
indirectly, have been described in the published literature. Poor work environmental conditions, $[15,16]$ poor perception of work conditions [15] and presence of disease or adverse health conditions among the workers $[17,18]$ have been identified as the general predisposing factors. $[19,20]$ described three major risk factors for occupational hand injuries i.e. deficient use of protective measures, lack of work experience and worker-related factors (drowsiness, inattention etc.). In our study bone fracture was the most frequently encountered type of injury. The rate traumatic amputation of hand and fingers was $1.23 \%$ and $11.42 \%$ respectively. Published studies have reported different patterns and distribution of injuries. Some studies have reported laceration type injuries as the most common, followed by crush injuries, fractures and amputations $[6,8,18]$. Stanbury et al. [10] analysed work-related amputations, and found that single digit amputations constituted the leading type (71\% of the total amputations) while hand amputations were around $1.2 \%$. Further multicentre study is recommending.

\section{Conclusion}

Hand trauma predominantly affects young males who have occupational exposure to different machines. It is associated with a high rate of traumatic amputation of hand and digits. Most of the cases result from avoidable occupational hazards. In this study we conclude that males, urban workers, labourers and manual workers are more likely to get hand injury. Hand injury is not a problem of patients only but also a problem of dependent family members. We can save hands by proper trainings and should be aware of safety measures. Separate hand care units should be established which at the present do not exist in this country. NGOs should realize this and should come up with this issue and should press the government by taking this issue through media.

\section{References}

1. Hung LK, Choi KY, Yip K, Chan J, Leung PC (1997) Recent changes in the pattern of hand injuries in Hong Kong: a regional hospital survey. Hong Kong Medical Journal 3(2): 141-148.

2. Chow CY, Lee H, Lau J, Yu IT (2007) Transient risk factors for acute traumatic hand injuries: a case crossover study in hong kong. Occup Environ Med 64(1): 47-52.

3. Rey P, Bousquet A (1995) Compensation for occupational hand injuries and its effect upon prevention at the work-place. Ergonomics 38(3): 475-86.

4. Simon RR, Slobodkin D (1996) Injuries to the wrist and hand. Emergency Medicine 4: 1217-1235.
5. Lese AB (2006) Hand Injury, Soft Tissue. Emergency Medicine.

6. Metcalf W, Whalen W (1957) The surgical, social and economic aspects of hand injury. Journal of Bone and joint Surgery 39: 317-324.

7. Hill C, Riaz M, Mozzam A, Brennen MD (1998) A Regional Audit of Hand and Wrist Injuries. J Hand Surg Br 123(2): 196-200.

8. Kleinfeld F, Bassler R (1998) Clinical picture and pathomor-phology of traumatic Hand injuries. Journal of Orthopaedic Research 16(3): 309313.

9. Choyce MQ Potts M, Maitra AK (1998) A profile of sports hand injuries in an accident and emergency department. Journal of Accident and Emergency Medicine 15(1): 35-38.

10. German G, Sherman R, Levin LS (1999) Decision making in reconstructive surgery upper extremity, Springer, USA.

11. Rosberg HE, Dahlin LB (2004) Epidemiology of hand injuries in a middle-sized city in Southern Sweden: a retrospective comparison of 1989 and 1997. Scand J Plast Reconstr Surg Hand Surg 38(6): 347-355.

12. Gustafsson M, Ahlstrom G (2006) Emotional distress and coping in the early stage of recovery following acute traumatic hand injury: a questionnaire survey. Int J Nurs Stud 43 (5): 557-565.

13. Khan H (2006) Child hood in Pakistan: the situation, the challenges and the response. The journal of the Pakistan Medical association 31(2): 5.

14. Dias JJ, Garcia Elias M (2006) Hand injury cost. Injury 37(11): 10711077.

15. Ghosh AK, Bhattacherjee A, Chau N (2004) Relationships of working conditions and individual characteristics to occupational injuries: a case-control study in coal miners. J Occup Health 46(6): 470-480.

16. Gauchard G, Chau N, Mur JM, Perrin P (2001) Falls and working individuals: role of extrinsic and intrinsic factors. Ergonomics 2001; 44(14): 1330-1339.

17. Bhattacherjee A, Chau N, Sierra CO, Legras B, Benamghar L, et al. (2003) Relationships of job and some individual characteristics to occupational injuries in employed people: a community-based study. J Occup Health 45(6): 382-391.

18. Chau N, Mur JM, Benamghar L, Siegfried C, Dangelzer JL, et al. (2004) Relationships between certain individual characteristics and occupational injuries for various jobs in the construction industry: a case-control study. Am J Ind Med 45(1): 84-92.

19. Sorock GS, Lombardi DA, Hauser RB, Eisen EA, Herrick RF, et al. (2001) A case-crossover study of occupational traumatic hand injury: methods and initial findings. Am J Ind Med 39(2): 171-179.

20. Sorock GS, Lombardi DA, Hauser R, Eisen EA, Herrick RF, et al. (2004) A case-crossover study of transient risk factors for occupational acute hand injury. BMJ Publishing Group Ltd 61(4): 305-311. 